\title{
Exploring the Use of a Stereoscopic 360 Degree Learning Environment for Business Education
}

\author{
K. W. Lau and P. Y. Lee
}

\begin{abstract}
The tremendous development and popularity of portable immersive virtual technologies currently has given chance to educators to develop any kind of innovative educational practices. Educators are able to conduct a situated learning approach virtually beyond the boundaries of traditional classroom and workshop practices. This research aimed to enhance our business students' learning achievement with an effective situated learning programme, and in order to develop their professional knowledge and problem solving skills through the use of a designed stereoscopic 360 degree learning environments. There is hitherto little research on studying the similar subject. Thus, a quasi-experimental research method was applied to look at students' learning achievements in order to contribute to the future development of similar innovative pedagogies. The findings showed that students' learning achievements in the stereoscopic 360 degree learning environment are better than those traditional classroom/workshop practices. However, the results also showed that the use of this new platform is not yet promising to motivate and prepare them for independent learning and self-evaluation. Further investigation is needed for actual implementation in business education.
\end{abstract}

Index Terms-Situated learning, immersive environment, stereoscopic technology, business education.

\section{INTRODUCTION}

Because of the tremendous developments in electronic learning environments and the virtual technologies currently, such as the portable stereoscopic 3D environment (Oculus), virtual reality and mobile learning platforms, educators are able to conduct a situated learning approach virtually beyond the boundaries of traditional education and training programmes as well as enhancing learners' learning achievement in a highly interactive manner. Indeed, most of the advanced learning systems are ready in the market for implementing any kind of innovative learning approach for business education. Our research team believes that the use of stereoscopic 360 degree learning environment (with Oculus system) is able to enhance university students' learning achievement in authentic business studies through a situated learning approach. However, to enhance business students' learning outcomes and experiences through the use of technologies is always a key concern in various relevant

Manuscript received February 4, 2018; revised August 23, 2018. This work was supported in part by the U.S. Department of Commerce under Grant BS123456 (sponsor and financial support acknowledgment goes here).

K. W. Lau is with the Hong Kong Polytechnic University, Boulder, CO 80305 USA (e-mail: laukungwong@gmail.com).

Y. Lee is with the Hong Kong Polytechnic University, Tsukuba, Japan (e-mail: tcrobert@polyu.edu.hk). studies [1], [2]. Therefore, this research is introduced to enhance our business students' learning achievement with an effective situated learning programme on Omni-Channel retailing, and in order to develop their professional knowledge and problem solving skills through the use of a designed stereoscopic 360 degree learning environments.

Based on these key aims, this research contributed five long-term impacts on academic and professional practice:

1) Understanding the possible ways of applying stereoscopic 360 degree learning environment in business education for further academic and professional development of professional education;

2) Identifying the knowledge scopes and relationships between situated simulation practices and business students' training programmes;

3) Exploring the important factors in the use of $360 \mathrm{Vs}$ for future implementation in distributed learning practices;

4) Establishing $360 \mathrm{Vs}$ training models for organizational learning in the fashion retailing industries; and

5) Providing educators with empirical evidence to support arranging, developing and allocating resources for learning in immersive environment.

This learning programme focused on teaching business students with an integrated retailing and sales approach for all channels and/or the value-adding practices in the sales cycle of product. This project emphasizes the use of 360 degree/immersive videos $(360 \mathrm{~V})$ in a series of situated learning activities. $360 \mathrm{~V}$ is a video recording technique where view in every direction is recorded by an omnidirectional camera at the same time. Viewers could use 360 gears and stereoscope-style headset to watch the videos in a panorama and interactive manner.

In this programme, the research team developed a set of six $360 \mathrm{Vs}$ to help business students to learn and experience the up-to-date Omni-Channel retailing approach and knowledge within a situated learning environment by some real-world practices. The content of these proposed $360 \mathrm{Vs}$ covered the key knowledge and skills of Omni-Channel and Me-too strategy, such as (1) inventory management; (2) customer experience and loyalty; (3) productive technology investments; and (4) customer retention. The situated learning pedagogical approach is adopted in this project by providing students with a real-world simulation during their learning process. Participated students are given a chance not only learning relevant knowledge, but also experience the real-world practices. The duration of each $360 \mathrm{Vs}$ is 10 minutes and totally 40 minutes of videos will be produced (See Fig. 1).

To be specific, this programme is neither a distance learning nor establishing a virtual learning community for 
business students' self-directed learning practices. A situated learning approach is applied in this programme of which students are encouraged to actively involve in both real-world store practices and virtual learning activities. The research team believes the situated learning approach is able to enhance the quality of business education in particular to some technological-related focuses. In order to evaluate the effectiveness of this innovative learning tool as well as students' learning achievement in Omni-Channel retailing practices. A quasi-experimental research method was applied to look at students' learning achievement.

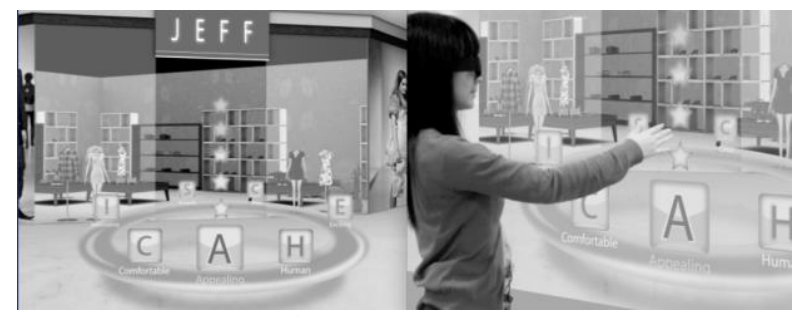

Fig. 1. A sample of the $360 \mathrm{Vs}$ videos in business studies.

\section{Situated LEARNING IN VIRTUAL ReALity: A CONSTRUCTIVISTS' PERSPECTIVE}

Constructivists [3] have given us some key factors on developing an effective learning models, they are (i) a challenging learning environment; (ii) authentic and real-world tasks; (iii) rich and diverse learning content; (iv) constructed knowledge; and (v) social negotiation and sharing in learning process. In particular to the use of social negotiation, Prawat and Floden [4] believe that it is a key for learners to understand the others' reality. Likewise, a constructivists' approach [5] of developing a learning environment would also involve the use of strong visualization and real-world simulations. The power of using situated learning, according to Prensky [6], is to provide learners with a simulated learning environments and tasks that they might able to face in the future. In this case, the use of virtual environment could help learners to explore extreme situations in a safety and well-constructed manner [7]. Early constructivists [8], [9] had indeed highlighted the virtual technologies have strong potentials in establishing a constructive learning environment. Any kind of virtual environment is able to implement constructive learning approach [10]. It is important to note that, an immersive virtual reality has the potential to be an effective learning environment [11] in particular to help learners to build up their mental model for real-world simulation [12]. Beside, an effective design of an immersive virtual environment is also able to provide learners with a 'playful' learning experience during their learning process [13]. Agree to other researchers [14]-[16], our research team believes that the use of immersive virtual environment (e.g. stereoscopic 360 degree learning environment) is promising to enhance learners' active and playful learning experiences. Nonetheless, despite most of the previous E-learning research [2], [17] are focusing on developing computer simulations in virtual reality, there is hitherto little research on studying the use of stereoscopic 360 degree learning environment had been found.

\section{RESEARCH DESIGN}

This research investigated a group of business students' learning achievement in the designed stereoscopic 360 degree learning environment. The project team has evaluated the existing learning practices in university level, Omni-channel retailing learning materials and use of the 360-degree/immersive technologies for situated learning. In order to deepen our understanding of the use of the said technology in learning and teaching practices, a quasi-experimental research method was applied to compare the experimental group and control group. Quantitative data was collected to examine the students' learning achievement in learning and knowledge acquisition on Omni-Channel retailing practices in a situated learning environment. The investigation divided 40 business students into (1) experiment group; and (2) control group. The experiment group applied the modified learning materials and situated learning activities in the stereoscopic 360 degree learning environment (in a form of Oculus VR), and the control group applied traditional lecturing and workshop practices. After four weeks (total 12 teaching hours) of learning experiment, the project team examined the learning effectiveness and outcomes (by a standard test and students' reflective journal) on both experimental and control groups by using a Criterion-referenced Assessment (CRA) scale in their assignments. All participants were asked to attend a test and submit a 500-word reflective journal on their learning process and evaluation. The CRA was applied as a post-test to assess students' learning outcomes. CRA is applied to study their learning achievements from FOUR perspectives, they are (1) Professional Knowledge (PK)- it assesses students' competency of learning by doing in real-world practices; (2) Problem Solving (PS) - it assesses students' ability to solve real-world business problems; (3) Independent Learning (IL) - it assesses students' self-motivation in furthering knowledge, skills and interests in related subject matters; and (4) Critical Reflection (CF) - it assesses students' ability to evaluate their process of learning in order to make improvements. In order to avoid bias over the assessment period, three independent makers were employed to assess students' (from both groups) final result and written journals.

The study sample was (total 40 business students in undergraduate level) divided into two groups: 20 students were in experiment group, and 20 students were in control group. The experimental group was experienced the modified mode of study by using the set of six $360 \mathrm{Vs}$, while the control group was experienced the traditional lecture/workshop mode. The assignment for both groups were remained the same. It is important to note that the indicated content of the programme remaining the same across two groups.

Regarding the recruitment of participants for this research, the Criterion-based Selection [18] and the Purposeful Sampling [19] were used to select the 40 participants. The criteria for selecting appropriate participants were that they should be (1) second year of business students in undergraduate level; and (2) business students with certain experience in E-learning practices. 


\section{DATA ANALYSIS AND DiSCUSSION}

The research data and findings are based on the 40 business students (undergraduate level) in both experiment and control groups analyzed by ANOVA analysis. In this research, the CRA is applied to examine employees' learning outcomes from the aforesaid four marking perspectives which are (1) professional knowledge; (2) problem solving skills; (3) independent learning; and (4) critical reflection. The outcomes of the indicators professional knowledge and problem solving skills were assessed by the post-test, whereas the indicators independent learning and critical reflection were assessed by written format of students' reflective journals. Three independent instructors in the same subject marked all these measures. The average of the students' learning achievements in experimental groups is $74 \%(\mathrm{~m}=$ 73.63 , s.d. $=4.37)$, whereas the students' learning performances in control group is $65 \%(\mathrm{~m}=65.14$, s.d. $=4.33)$ This shows that two experimental group have a high effectiveness of learning achievement in this study in the stereoscopic 360 degree learning environment. Table 1 shows the percentage of students' learning performances from the four marking perspectives.

Students in the experimental group demonstrated a better learning achievement (around 9\%) than those students in the control group. It implies that the conventional lecture/workshop pedagogical practices in business studies (in particular to technological subject focus such as the Omni-channel retailing) is possibly replaced or enhanced by the use of stereoscopic 360 degree learning environment.

TABLE I: STUDENTS' LEARNING ACHIEVEMENT BY CRA

\begin{tabular}{|c|c|c|c|c|c|c|c|c|}
\hline & \multicolumn{4}{|c|}{ Experimental Group } & \multicolumn{4}{|c|}{ Control Group } \\
\hline & $\begin{array}{c}\text { PK } \\
(n=20)\end{array}$ & $\begin{array}{c}\text { PS } \\
(n=20)\end{array}$ & $\underset{(n=20)}{\text { IL }}$ & $\begin{array}{c}\mathrm{CF} \\
(n=20)\end{array}$ & $\begin{array}{c}\text { PK } \\
(n=20)\end{array}$ & $\begin{array}{c}\text { PS } \\
(n=20)\end{array}$ & $\begin{array}{c}\text { IL } \\
(n=20)\end{array}$ & $\underset{(n=20)}{\mathrm{CF}}$ \\
\hline $\mathrm{m}$ & 77.42 & 77.34 & 69.64 & 70.12 & 61.52 & 63.24 & 66.78 & 69.04 \\
\hline s.d. & 4.79 & 4.01 & 4.88 & 3.78 & 4.12 & 4.44 & 4.56 & 4.20 \\
\hline
\end{tabular}

It is important to note that the students in experimental group achieved better learning achievements in the indicators PK $(\mathrm{m}=77.42$, s.d. $=4.79)$ and PS $(\mathrm{m}=77.34$, s.d. $=4.88)$ which related to professional knowledge and problem solving skills, whereas the control group in these two indicators have only achieved $(\mathrm{m}=61.52$, s.d. $=4.12)$ in professional knowledge and $(\mathrm{m}=63.24$, s.d. $=4.44)$ in problems solving skills respectively. The experiment group has performed more than $6 \%$ higher than the control group in the indicator professional knowledge. It implies that the use of stereoscopic 360 degree learning environment is helpful in particular to deliver professional knowledge than in normal classroom setting. Regarding the indicator professional knowledge, the experiment group also reached a better result apparently than the control group. The training of problem solving skill is also positive by implementing this immersive environment. Nonetheless, these results proved that the use of stereoscopic 360 degree learning environment and its pedagogical approach is able to enhance students' learning achievement by providing them with a situated learning environment in learning professional knowledge and tackling real-world problems. However, in view of the rest two indicators independent learning and critical reflection, which relates to students' self-motivation, sense of independent learning and evaluation skills, the control group has achieved $(\mathrm{m}=66.78$, s.d. $=4.56)$ in independent learning and $(\mathrm{m}=69.04$, s.d. $=$ $4.20)$ in critical reflection which demonstrated a similar result that the experimental group had achieved $(\mathrm{m}=69.64$, s.d. $=$ $4.88)$ in indicators independent learning and $(\mathrm{m}=70.12$, s.d. $=3.78$ ) in critical reflection. Although both experimental and control groups achieved a similar effective learning achievements in these two perspectives (indicators independent learning and critical reflection), there are difference of scores variation between the four marking perspectives. This result implies that the use of stereoscopic 360 degree learning environment is not yet promising to enhance students' independent learning processes and critical reflection skills. However, this result also can be interpreted that the use of 360 degree learning environment could help students to develop their independent learning and critical reflection on the subject knowledge as effective as the normal classroom setting does. It implies that the use of this new environment is possible to replace the traditional pedagogy in school. Nonetheless, further investigation is needed, in particular to these two key perspectives, for actual implementation in business education.

\section{CONCLUSION AND IMPLICATIONS}

This research studied the possibility of using stereoscopic 360 degree learning environment for situated learning in business subjects. The key research question of this study is asking whether the use of stereoscopic 360 degree learning environment is able to enhance business students' learning achievement by a situated learning approach. The findings showed that students' learning achievements in the stereoscopic 360 degree learning environment are better than those traditional classroom/workshop practices. However, the results also showed that the use of this new platform is not yet promising to motivate and prepare them for independent learning and self-evaluation. Moreover, it is therefore, the researchers urge the future development of situated learning approach should also consider the characteristics of different learners in particular to their prior knowledge, computer attitudes and interest.

Similar to some prior research on virtual reality [11], [20], the use of any kind of virtual reality in situated learning enriched learners' learning experiences. The result of this research echoes to some previous research [21] that the use of stereoscopic 360 degree learning environment and the situated learning approach help students to explore their new behaviors, repeat their new experience and adjust their approach based on the learning achievements. Students' post-test results showed that they were innovatively integrated professional knowledge and problem solving skills learnt from the programme to tackle real-world problem. To conclude, the use of stereoscopic 360 degree learning environment is positive by providing university students with (1) a simulated learning environment for any kind of situated and exploratory learning activities; (2) a unique learning experience; and (3) behavior changes for future practices. The finding of this research could be anticipated to contribute to 
both research and teaching practices in all kind of educational sectors. The explored knowledge on designing and applying stereoscopic 360 degree learning environment in this research help educators to identify future research perspective as well as developing situated learning pedagogy in immersive learning environment.

In conclusion, although the use of the stereoscopic 360 degree learning environment is empirically find not yet significant in developing business students' independent learning and critical thinking skills, however, the reasons behind might be, university students are different from other junior students that they are more eager to acquire knowledge (e.g. business knowledge) from social media platform in particular to Facebook, youtube and professional blogs, this new immersive environment might not be familiar with them in daily practices. All in all, real-world practices are always an effective teaching and learning ways for business students. This research has demonstrated an authentic case of exploring and developing new type of virtual learning platform for business studies. In this research, an authentic case has been established and proven for other future attempts on developing stereoscopic 360 degree videos and other immersive learning environments. In addition, because of the tremendous development of these technologies and other game-based learning approaches are potentially changing the entire university and business education arena. Moreover, it is important to note that the stereoscopic 360 degree learning environment is not a lecture theatre where every learner sits properly and pays attention to instructional information, but a flexible learning platform with a set of self-directed learning activities for real-world practices. It is therefore, to design this immersive learning environment, educators should pay attention on providing business students with a sense of embodiment, a sense of being in real-world setting instead of only making some fancy visuals happen on the screen. An immersive learning environment is not merely a mixture of cyberspace and educational stimulation, but a learning platform that facilitates independent and collaborative learning activities among students and virtual objects.

All in all, this research suggests there are three major domains have to explore in order to cope with the challenges, they are;

1) It is essential to study the theoretical framework of designing learning activities and pedagogies in particular to develop students' independent learning as well as critical thinking skills;

2) It is crucial to explore the effective use of stereo3D visualization and its potentials in situated learning practices; and

3) It is always important to understand students' learning experiences in diverse digital platforms.

\section{REFERENCES}

[1] K. W. Lau, "A study of students' virtual learning experiences in creativity training in design education: An empirical research in a shared virtual reality," Journal of Design Research, vol. 10, no. 3, pp. 170-188, 2012.

[2] D. Stott. (2007). Attending medical school in virtual reality. Student BMJ. [Online]. Available: http://student.bmj.com/issues/07/12/news/431.php

[3] A. Woolfolk, Educational Psychology, Boston, Allyn \& Bacon, 1998.
[4] R. S. Prawat and R. Floden, "Philosophical perspectives on constructivist views of learning," Education Psychologist, pp. 37-48, 1994.

[5] D. H. Jonassen, "Designing constructivist learning environments," Instructional Design Theories and Models: A New Paradigm of Instructional Theory, vol. 2, pp. 215-239, Mahwah, NJ: Lawarence Erlbaum Associates, Publishers, 1999.

[6] M. Prensky, "Computer games and learning: Digital game-based learning," Handbook of Computer Game Studies, London, The MIT Press, pp. 97-122, 2005.

[7] J. S. Brown and D. Thomas, "You play world of warcraft? You're hired!" Wired, vol. 14, no. 4, 2006.

[8] W. Winn, "A conceptual basis for educational applications of virtual reality," Technical Report TR 93-9, 1993.

[9] R. B. Gabbard, "Constructivism, hypermedia, and the world wide web," CyberPsychology \& Behavior, vol. 3, pp. 103-110, 2000.

[10] F. Mantovani, "VR learning: potential and challenges for the use of 3D environments in education and training," Towards Cyber Psychology: Mind, Cognition and Society in the Internet Age, pp. 207-225, Amsterdam: IOS Press, 2001.

[11] S. Stoerger, "Virtual worlds, virtual literacy: An educational exploration," Knowledge Quest, vol. 36, no. 3, pp. 50-56, 2008.

[12] M. C. Salzman et al., "A model for understanding how virtual reality aids complex conceptual learning," Presence, vol. 8, pp. 293-316, 1999.

[13] S. Frietas. (2006). Learning in immersive worlds: A review of game based learning. [Online]. Available: http://www.jisc.ac.uk/media/documents/programmes/elearninginnova tion/gamingreport_v3.pdf

[14] J. G. Jones et al., "3-dimensional online learning environments: Examining attitudes toward information technology between students in internet-based 3-dimensional and face-to-face classroom instruction," Educational Media International, vol. 42, no. 3, pp. 219-236, 2005.

[15] S. Barab et al., "Making learning fun: quest Atlantis, a game without guns," Educational Technology Research and Development, vol. 53, no. 1, pp. 86-107, 2005.

[16] L. F. Johnson and A. H. Levine, "Virtual worlds: Inherently immersive, highly social learning spaces," Theory into Practice, vol. 47, pp. 161-170, 2008.

[17] A. Gaggioli, "Using virtual reality in experimental psychology," Towards Cyberpsychology: Mind, Cognition and Society in the Internet Age, pp. 157-174, Amsterdam: IOS Press, 2001.

[18] M. D. LeCompte and J. Preissle, "Toward an ethnology if student life in schools and classrooms: Synthesizing the qualitative research tradition," The Handbook of Qualitative Research in Education, San Diego, CA: Academic Press, pp. 815-859, 1992.

[19] M. Q. Patton, How to Use Qualitative Methods in Evaluation, Newbury Park, CA: Sage, 1987.

[20] J. Blascovich and J. Bailenson, "Immersive virtual environments and education simulations," Virtual Decisions: Digital Stimulations for Teaching Reasoning in the Social Sciences and Humanities, pp. 229-253, New Jersey: Lawrence Erlbaum Associates, Inc., 2006.

[21] N. Rutten et al., "The learning effects of computer simulations in science education," Computers \& Education, vol. 58, no. 1, pp. 136-153, 2012.

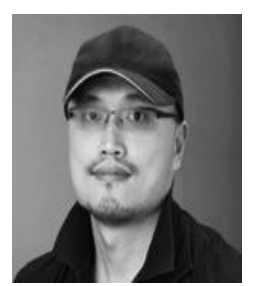

Kung Wong Lau is an assistant professor at the Institute of Textiles and Clothing, the Hong Kong Polytechnic University. He obtained his first degree from the Hong Kong Polytechnic University, and finished his MSc and $\mathrm{PhD}$ from the University of Hong Kong and the University College London respectively in the areas of experiential studies in virtual reality and creativity education. $\mathrm{He}$ is interested in studying distributed organizational learning in virtual reality as well as creativity and strategic design thinking training for business practices. $\mathrm{He}$ is currently being an advisor of the UNESCO Arts in Education Observatory for the Research in Local Cultures and Creativity in Education. $\mathrm{He}$ was the Chief Examiner from the Hong Kong Examinations and Assessment Authority and the Subject Specialist (Creative Industry) from the Hong Kong Council for Academic Accreditation. He is also a member of the British Educational Research Association and editorial members of diverse international journals. He has published over 75 research papers in diverse international referred journals, book chapters and conferences for the said research domains. 


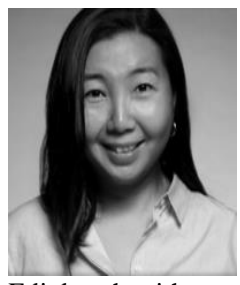

Pui Yuen Lee is an assistant professor in the School of Design with expertise in advertising design. She teaches research methods and strategic advertising courses for bachelor and master degree. She also supervises doctoral thesis on topics examining advertising, management, creative practices in relation to media technology and innovation.

Dr. Lee receives her PhD from the University of Edinburgh with research on advertising creativity, change management of advertising organizations. She is interested to investigate the changing roles of creative professionals play within society and how digital and innovative technology informed contemporary advertising practices.

Dr. Lee processes both academic and industrial experiences in advertising and design. She worked as communication designer and advertising creatives in multinational advertising agencies (O\&M, FCB, DY\&R). In 2008, Lee pursued her teaching and research life and had served at various institutions including City University of Hong Kong, Hong Kong Baptist University and currently at the Hong Kong Polytechnic University. 